\title{
Critical appraisal of international guidelines for the screening and treatment of asymptomatic peripheral artery disease: a systematic review
}

\author{
Qinchang Chen ${ }^{1 \dagger}$, Lingling $\mathrm{Li}^{1+}$, Qingui Chen ${ }^{2}$, Xixia Lin ${ }^{3}$, Yonghui $\mathrm{Li}^{3}$, Kai Huang ${ }^{3^{*}}$ and Chen Yao ${ }^{1^{*}}$ (D)
}

\begin{abstract}
Background: Peripheral artery disease (PAD) is often asymptomatic but increases the risk of developing cardiovascular events. Due to the uncertainties regarding the quality of related guidelines and a lack of clear-cut evidence, we performed a systematic review and critical appraisal of these guidelines to evaluate their consistency of the recommendations in asymptomatic PAD population.

Methods: Guidelines in English between January 1st, 2000 to December 31th, 2017 were screened in databases including Medline via PubMed, EMBASE, the G-I-N International Guideline Library, the National Guidelines Clearinghouse, the Canadian Medication Association Infobase and the National Library for Health. Those guidelines containing recommendations on screening and treatment for asymptomatic PAD were included, and three reviewers evaluated the quality of the guidelines using Appraisal of Guidelines Research and Evaluation (AGREE) II instrument. Related recommendations were then fully extracted and compared by two reviewers.

Results: Fourteen guidelines were included finally and the AGREE scores ranged from 39 to $73 \%$. Most of included guidelines scored low in Rigor of development and Editorial independence, and only two guidelines (ACCF/AHA, AHA/ACC) reached the standard on Conflict of Interest from Institute of Medicine (IOM). Eight guidelines recommended screening at different strength while the others found insufficient evidence or were against screening. Conflicting recommendations on treatment were found in the target value of the lipid lowering and antiplatelet therapy. The treatment policies in three guidelines (BWG, CEVF, ESC) appeared more aggressive, but they had low transparency between guideline developer and industry or did not reach the standard of IOM.

Conclusions: Current guidelines on asymptomatic PAD varied in the methodological quality and fell short of the standard in the rigor of development and editorial independence. Conflicting recommendations were found both on the screening and treatment. More effort is needed to provide clear-cut evidences with high quality and transparency among guideline developer and industry.
\end{abstract}

Keywords: Peripheral artery disease, Guidelines, Screening, Treatment

\footnotetext{
*Correspondence: huangk37@mail.sysu.edu.cn; yaochen@mail.sysu.edu.cn

${ }^{\dagger}$ Qinchang Chen and Lingling Li contributed equally to this work.

${ }^{3}$ Department of Vascular Surgery, Sun Yat-sen Memorial Hospital, Sun Yat-sen

University, No.33, Yingfeng Road, Guangzhou, China

${ }^{1}$ Department of Vascular Surgery, the First Affiliated Hospital, Sun Yat-sen

University, No.58 Zhongshan Road 2, Guangzhou, China

Full list of author information is available at the end of the article
}

(c) The Author(s). 2019 Open Access This article is distributed under the terms of the Creative Commons Attribution 4.0 International License (http://creativecommons.org/licenses/by/4.0/), which permits unrestricted use, distribution, and reproduction in any medium, provided you give appropriate credit to the original author(s) and the source, provide a link to the Creative Commons license, and indicate if changes were made. The Creative Commons Public Domain Dedication waiver (http://creativecommons.org/publicdomain/zero/1.0/) applies to the data made available in this article, unless otherwise stated. 


\section{Introduction}

Peripheral arterial disease (PAD) is defined as an atherosclerotic process that leads to stenosis and occlusion in non-cerebral and non-coronary arteries [1]. More than 200 million patients worldwide have PAD and the incidence of PAD has increased to nearly $20 \%$ in people over 70 [2, 3]. Following coronary heart disease and stroke, PAD has become the third cause of atherosclerotic vascular morbidity [2]. Further prevalence data demonstrates that the number of asymptomatic PAD patients is several times larger than that of the PAD patients with intermittent claudication $[1,4]$. Though no obvious clinical symptoms, asymptomatic PAD patients still have a similar risk of premature mortality to that of symptomatic PAD patients, and it is much higher than that of those without PAD [5]. Early detection and treatment of asymptomatic PAD not only prevent its progression, but also lower the risk of developing cardiovascular events, such as myocardial infarction and stroke.

However, sufficient attention has not been paid to asymptomatic PAD, though several studies have been conducted to assess the value of screening for PAD patients $[6,7]$. But there was no randomized controlled trials (RCTs) that evaluate the benefits of screening for asymptomatic PAD only, which might lead to different judgement and conflicting recommendations on screening for asymptomatic PAD. The lack of convincing evidence also affects clinical decisions on the treatment for asymptomatic PAD. Thus, the recommendations on screening and treatment for asymptomatic PAD might be impacted by conflicts of interest since transparency among guideline writers was rather low $[8,9]$. According to a research in opioid for chronic pain, the organizations funded by opioid manufacturers appeared to oppose to draft guidelines on prescribing opioids, which is worthy of note [10].

In this study, we aimed to systematically appraise the guidelines on the screening and treatment for asymptomatic PAD and find out the agreements and the differences in the recommendations.

\section{Materials and methods}

The systematic review was performed according to the Cochrane methodology [11]. Clinical practice guidelines were defined as statements that contained recommendations with an objective to optimize patient care [12]. There were four steps in the process of the systematic review, including searching for guidelines, selecting guidelines according to specific criteria, appraising the quality of guidelines, and synthesizing recommendations.

\section{Search strategies}

A systematic search was performed to identify relevant guidelines containing the recommendations on management of asymptomatic PAD. We searched the Medline via PubMed and the EMBASE databases. Four guideline-related databases were also searched, including the Guidelines International Network (G-I-N) International Guideline Library, the National Guidelines Clearinghouse (United States), the Canadian Medical Association Infobase (Canada) and the National Library for Health (United Kingdom). The search was limited to guidelines published from January 1st, 2000 to December 31th, 2017. Details on the search strategies was provided in the Additional file 1: Table S1.

\section{Selection criteria}

Guidelines which met following criteria were selected. (1) The target population of the guideline includes asymptomatic PAD patients; (2) the guideline contains recommendations on the screening for asymptomatic PAD and/or treatment for asymptomatic PAD, including but not limited to exercise, pharmacological treatment, surgical treatment; (3) the guideline is available online; (4) the guideline is written in English; (5) the guideline is developed by related national or international academic organizations. Guidelines were excluded out of following reasons: (1) the guideline was not the latest version on the same topic and population; (2) the topic was only mentioned in the guidelines.

\section{Quality appraisal of the guidelines}

Three appraisers (QCC, LLL, CY) assessed the quality of the selected guidelines using the Appraisal of Guidelines Research and Evaluation (AGREE) II instrument. The AGREE II instrument is a 23-item tool with international certification which serves to evaluate the six domains of methodological quality of a guideline, including scope and purpose, stakeholder involvement, rigor of development, clarity of presentation, applicability, and editorial independence [13] (Additional file 2: Table S2). Each item was scored on a scale of 1 (strongly disagree) to 7 (strongly agree) by two appraisers (QCC, LLL). Each appraiser calculated a total score of each domain by adding up scores of all the items in a domain. If scores of the same item differed by more than 1 point between the two appraisers, a consensus meeting would be held to settle the dispute, during which the two appraisers explained the reason for their scores in sequence and then a third appraiser $(\mathrm{CY})$ determined the final score of the item. After that, the obtained score was transformed to a percentage score using the following formula [14]:

Obtained score-Minimum possible score

$$
\begin{aligned}
& \text { Maximum possible score-Minimum possible score } \\
& \quad * 100 \%
\end{aligned}
$$

Then each guideline was given a recommendation according to its percentage score. If most (4 or more) 
domains scored over $60 \%$, a guideline would be regarded as "strongly recommended for use in practice"; if scores of most domains ( 4 or more) ranged $30-60 \%$, the guideline would be regarded as "recommended for use with some modification"; if most of the domains (4 or more) scored less than $30 \%$, the guideline would be regarded as "not recommended for use in practice".

\section{Recommendations synthesis}

To examine the consistency of specific recommendations, we used a data extraction form (Additional file 3: Table S3) as previously described [15] to collect some important information from the guidelines, including years of publication, countries/regions, organizations, funding sources, and recommendations on the screening and/or treatments for asymptomatic PAD. The extractions were performed by one reviewer $(\mathrm{KH})$ and validated by another reviewer (QGC). Then the consistency of specific recommendations across different guidelines were assessed and the financial relationships between organizations that produced the guidelines and the biomedical industry were also analyzed.

\section{Results}

\section{Search results}

Three thousand two hundred forty-five citations were identified and 3126 citations were excluded after screening the titles and abstracts (Fig. 1). The remaining 119 citations were fully assessed through full texts and 105 citations were excluded because they were not clinical practice guidelines or consensus statements, or they were duplicated publications or older version of updated guidelines. Finally, 14 guidelines pertaining to the management of asymptomatic PAD were included [16-29].

\section{Characteristics of the guidelines}

Characteristics of the included guidelines were presented in Table 1. The guidelines were published between 2007 and 2017. Among them, 6 were developed by USA [16-18, 26, 28, 29], 2 were jointly developed by several European countries $[20,21]$, and 2 by international organizations named International Working Group on the Diabetic Foot (IWGDF) [24] and Trans-Atlantic Inter-Society Consensus (TASC) [27]. The other four guidelines were formulated in Belgium [19], Germany [22], Italy [23] and Korea [25]. Most guidelines contained recommendations on screening and treatment for asymptomatic PAD but three included recommendations on treatment only [17, 23, 25]. Only one guideline specifically targeted the asymptomatic PAD patients [26]. Seven guidelines reported that systematic literature reviews for the evidence base were performed before developing the guidelines $[17,18,21,22,24-26]$. Two guidelines reported that funding came from the pharmaceutical companies [16, 21], one from the government [28], one from

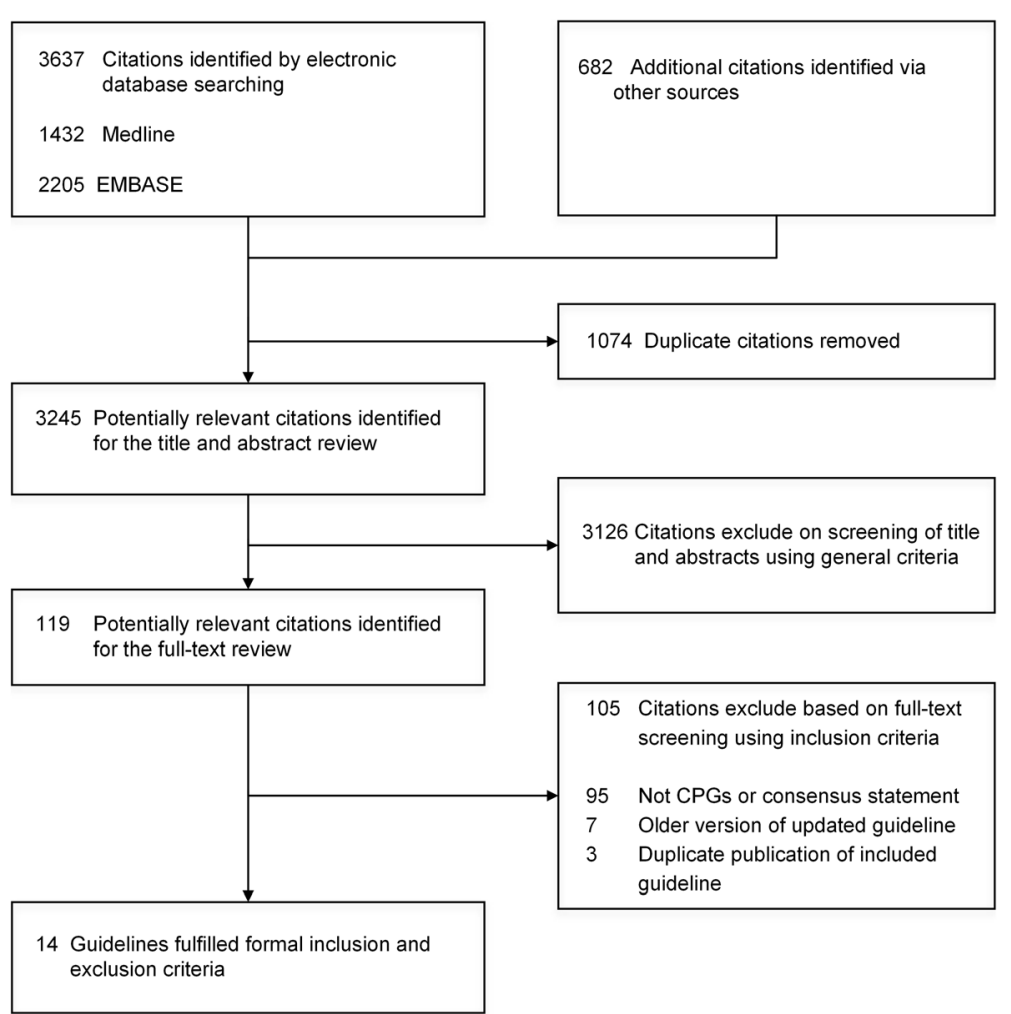

Fig. 1 Flow diagram of the identification process for guidelines on screening and treatment in asymptomatic peripheral artery disease 
Table 1 Characteristics of Included Guidelines of Asymptomatic PAD

\begin{tabular}{|c|c|c|c|c|c|c|c|c|}
\hline & Year & Country & Target population & $\begin{array}{l}\text { AGREE Rigor } \\
\text { score }\end{array}$ & Evidence base & Funding source & $\begin{array}{l}\text { COl of } \\
\text { Chairman }\end{array}$ & $\begin{array}{l}\text { COI of } \\
\text { members }\end{array}$ \\
\hline ACCF AHA & 2013 & USA & Management of PAD & 60 & NS & Pharmaceutical company & NO & $1 / 16$ \\
\hline ACCP & 2012 & USA & Antithrombotic therapy & 59 & $\begin{array}{l}\text { Systematic literature } \\
\text { review }\end{array}$ & $\begin{array}{l}\text { Government funding; Funding } \\
\text { Unrestricted educational grant } \\
\text { from pharmaceutical company }\end{array}$ & NO & $6 / 11$ \\
\hline AHA ACC & 2016 & USA & Management of PAD & 70 & $\begin{array}{l}\text { Systematic literature } \\
\text { review }\end{array}$ & No commercial sponsorship & No & $1 / 21$ \\
\hline BWG & 2007 & Belgium & $\begin{array}{l}\text { Diagnosis and treatment } \\
\text { of PAD }\end{array}$ & 59 & NS & NS & NS & NS \\
\hline CEVF & 2013 & Europe & Management of IC & 39 & $\begin{array}{l}\text { Consensus } \\
\text { statement }\end{array}$ & NS & NS & NS \\
\hline ESC & 2017 & Europe & $\begin{array}{l}\text { Diagnosis and treatment } \\
\text { of PAD }\end{array}$ & 70 & $\begin{array}{l}\text { Systematic literature } \\
\text { review }\end{array}$ & Pharmaceutical company & $1 / 2$ & $17 / 23$ \\
\hline GSA & 2016 & Germany & $\begin{array}{l}\text { Diagnosis and treatment } \\
\text { of PAD }\end{array}$ & 61 & $\begin{array}{l}\text { Systematic literature } \\
\text { review }\end{array}$ & NS & NS & NS \\
\hline ISD & 2014 & Italy & $\begin{array}{l}\text { Treatment of PAD in } \\
\text { diabetes }\end{array}$ & 60 & $\begin{array}{l}\text { Consensus } \\
\text { statement }\end{array}$ & NS & NS & NS \\
\hline IWGDF & 2016 & International & $\begin{array}{l}\text { Management of foot } \\
\text { ulcer in diabetes }\end{array}$ & 59 & $\begin{array}{l}\text { Systematic literature } \\
\text { review }\end{array}$ & NS & NS & NS \\
\hline KSIR & 2015 & Korea & $\begin{array}{l}\text { Interventional } \\
\text { recanalization of PAD }\end{array}$ & 72 & $\begin{array}{l}\text { Systematic literature } \\
\text { review }\end{array}$ & No commercial sponsorship & NS & NS \\
\hline SVS & 2014 & USA & $\begin{array}{l}\text { Management of } \\
\text { asymptomatic PAD }\end{array}$ & 73 & $\begin{array}{l}\text { Systematic literature } \\
\text { review }\end{array}$ & NS & $1 / 2$ & $7 / 11$ \\
\hline TASC & 2007 & International & Management of PAD & 70 & $\begin{array}{l}\text { Consensus } \\
\text { statement }\end{array}$ & NS & NS & NS \\
\hline USPSTF & 2013 & USA & Screening of PAD & 62 & NS & Government funding & NS & NS \\
\hline WHS & 2014 & USA & $\begin{array}{l}\text { Treatment of arterial } \\
\text { ulcer }\end{array}$ & 62 & NS & NS & NS & NS \\
\hline
\end{tabular}

Abbreviations: ACCF AHA American College of Cardiology Foundation, American Heart Association Task Force, AGREE Appraisal of Guidelines Research and Evaluation, AHA ACC American College of Cardiology, American Heart Association Task Force, BWG Belgian Working Group, CEVF Central European Vascular Forum, COI Conflict of Interest, ESC European Society of Cardiology, GSA German Society of Angiology, IC Intermittent Claudication, ISD Italian Societies of Diabetes, IWGDF International Working Group on the Diabetic Foot, KSIR Korean Society of Interventional Radiology, NS Not Stated, PAD Peripheral Arterial Disease, SVS Society for Vascular Surgery, TASC Trans-Atlantic Inter-Society Consensus, USPSTF US Preventive Services Task Force, WHS Wound Healing Society

both government and commercial companies [17], two received no commercial sponsorship [18, 25]; the others did not report the funding sources. Nine guidelines did not report any information about the conflict of interest (COI) in the chairman or the other members $[19,20,22-25,27-29]$.

\section{Guideline appraisal}

The final scores of six domains in each guideline were shown in Fig. 2. In order to visually gauge the strength and weakness of each domain between guidelines, we selected radar chart rather than histogram to present the result of guideline appraisal. The higher percentage meant the better quality in the domain and was mapped towards the outer perimeter (closer to $100 \%$ ). As it is shown in the graph, the guidelines from AHA/ACC, ESC, KSIR, SVS and TASC had relatively higher scores in most domains [17, 21, 25-36], [37], and most guidelines had higher scores in the domain 4 (Clarity of presentation). However, several guidelines scored low in domain 3 (Rigor of development) and domain 6
(Editorial independence). Some guidelines did not use systematic review protocol and there was still too low transparency between guideline writers and industry.

Six guidelines were regarded as "strongly recommended for use in practice", namely AHA/ACC, ESC, GSA, KSIR, SVS, TASC and WHS [18, 21, 22, 25-27]. The remaining guidelines were regarded as "recommended for use with some modification" and no guideline is regarded as "not recommended for use in practice".

\section{Recommendations on approaches to screening}

Ten guidelines contained the recommendations on screening for asymptomatic PAD [16, 18-22, 24, 28, 29]. The key recommendations were shown in Table 2. Guidelines differed slightly in the strength of recommendations on screening for asymptomatic population. Five guidelines $[19,21,22,24,29]$ strongly recommended the screening while three $[16,20,26]$ supported screening at the strength from moderated to strong. However, USPSTF guideline [28] did not provide the decision on screening 


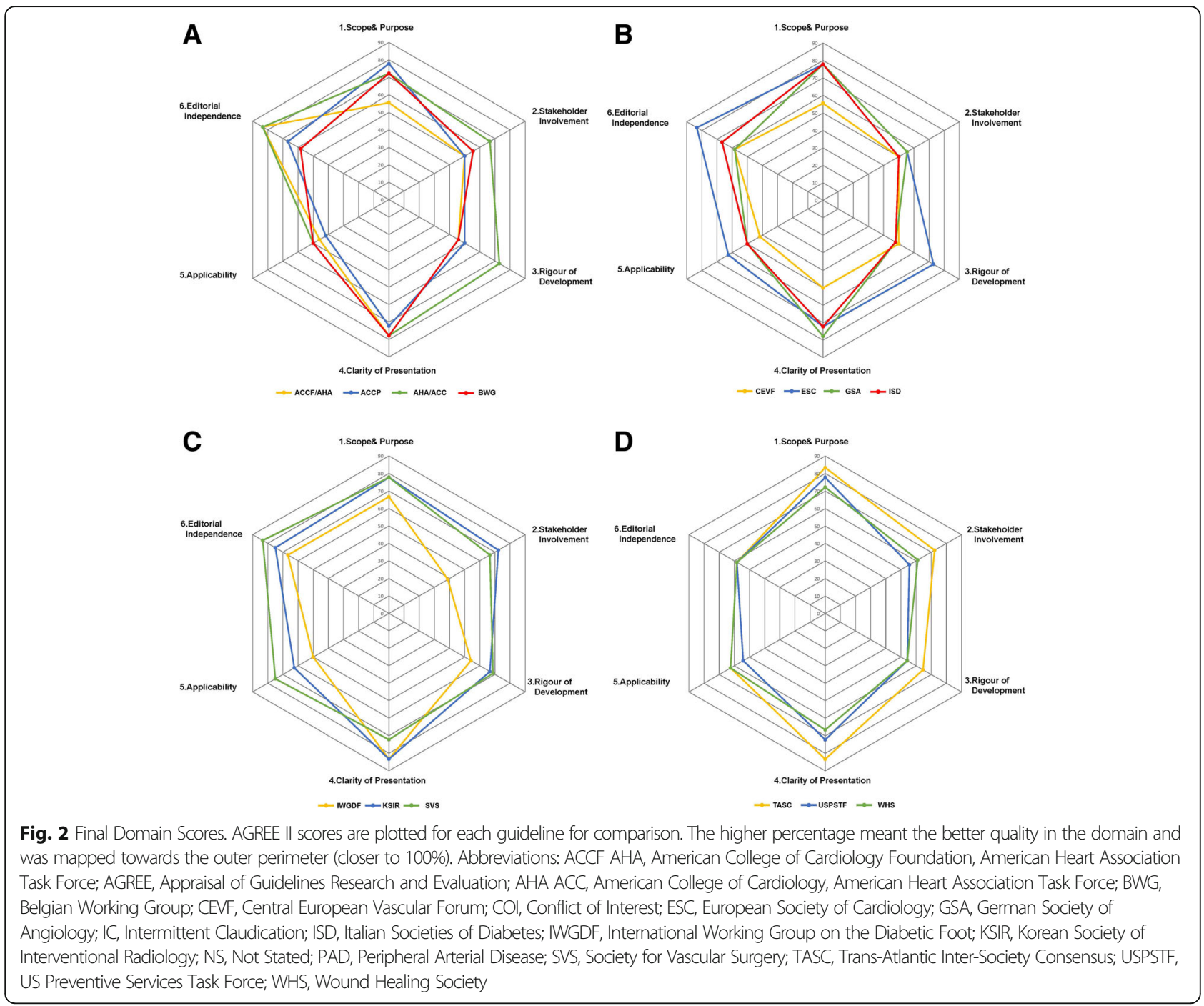

because of insufficient evidence and AHA/ACC guideline [18] considered that screening harmed the asymptomatic population. Apart from AHA/ACC guideline [18] considering non-invasive angiography, all the remaining guidelines recommended the invasive test, especially ABI test. Five guidelines $[16,19,20,22,24]$ provided the normal range of $A B I$ and made an agreement (0.9-1.3). The difference of target population was the age of the patients without elevated cardiovascular risk. Targeted ages of three guidelines $[19,20,26]$ were more than 70 years old while that of ESC guideline was 65 years old [21]. In terms of the further test, only four guidelines $[16,20,22,24]$ gave recommendations while the others did not. Among them, three guidelines recommended exercise ABI while GSA guideline considered no further test.

\section{Recommendations on approaches to treatment}

Table 3 showed the recommendations from eleven guidelines for the medical management of asymptomatic
PAD, including the secondly prevention and surgical treatment [16-23, 25-27]. The secondly prevention included smoking cessation, healthy diet, lipid lowering, hypertension treatment, diabetes treatment and antiplatelet therapy. Smoking cessation was recommended by five guidelines and there was no different recommendation [16, 19-21, 26]. For lipid lowering, two guidelines $[16,20]$ recommended to lower lipid but did not provide a target value. Three guidelines [19, 21, 27] recommended using stains to lower lipid but with different target value. ESC guideline [21] suggested LDL-C less than $70 \mathrm{mg} / \mathrm{L}$ while the others $[19,27]$ recommended $100 \mathrm{mg} / \mathrm{L}$. Hypertension treatment was recommended in four guidelines [16, 19-21]. ACCF/AHA guideline [16] regarded ACEI as the ideal drug and BWG guideline [19] provided the target value. Diabetes treatment was recommended in four guidelines [16, 19-21] and BWG guideline [19] provided more detail information. Antiplatelet therapy was recommended 


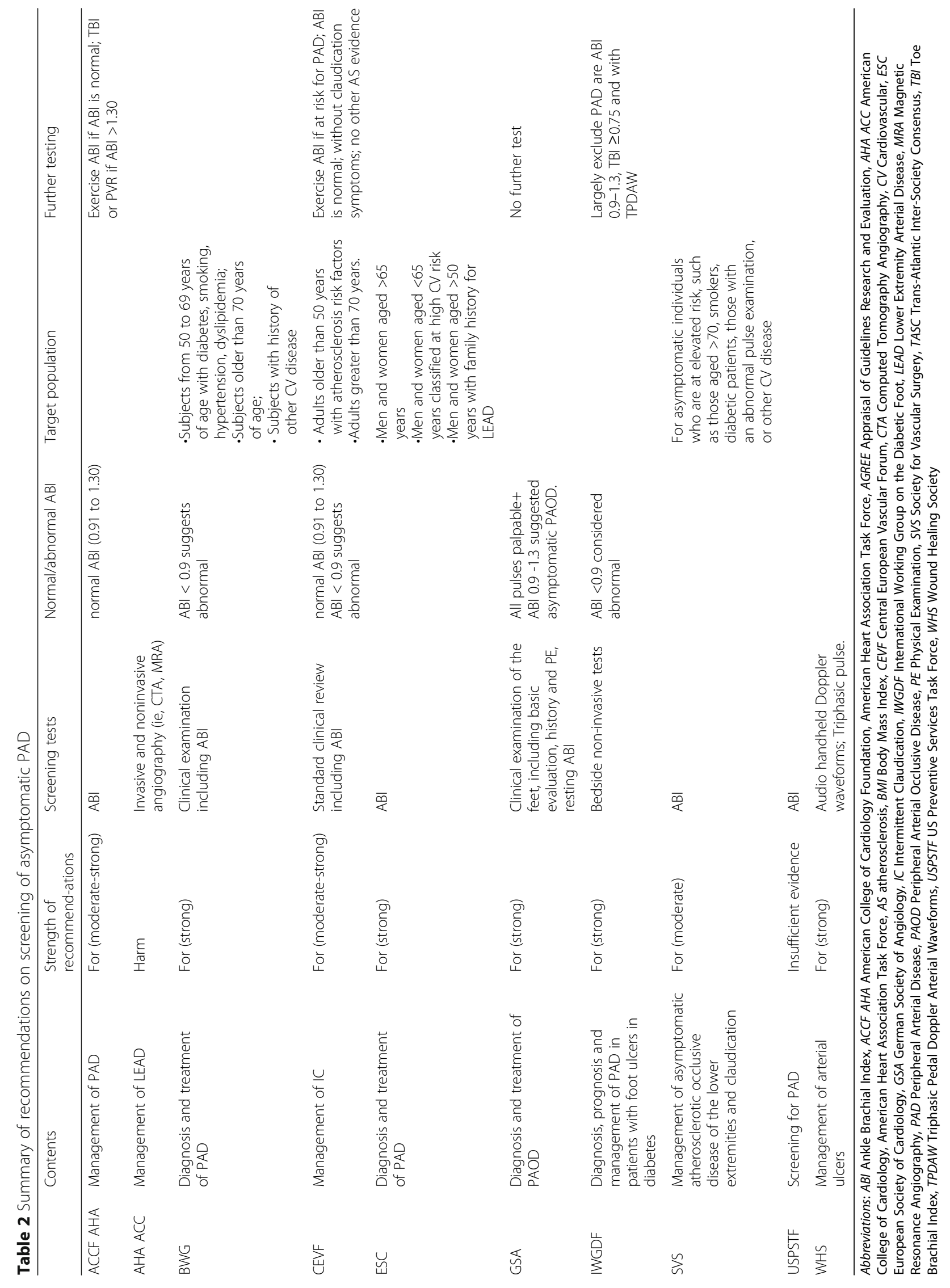




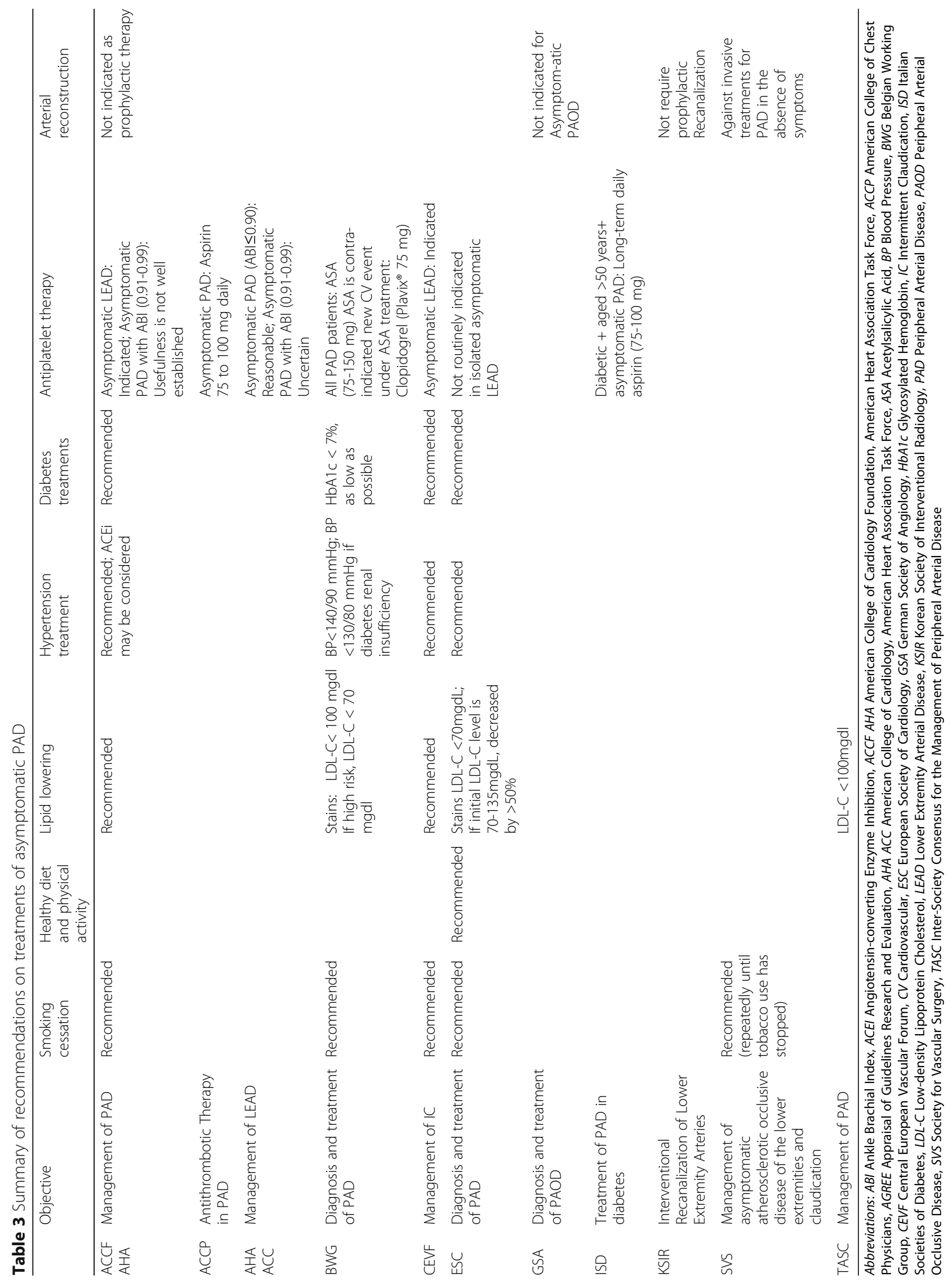


in seven guidelines [16-21, 23]. The controversy was at the administration dosage. ACCP and ISD guidelines [17, 23] considered $75-100 \mathrm{mg}$ for treatment while BWG guideline [19] recommended 75-150 mg. Arterial reconstruction was not recommended in four guidelines $[16,22,25,26]$ and there was not controversial recommendation.

\section{Discussion}

As far as we know, this is the first guideline appraisal on asymptomatic PAD. In summary, 14 guidelines were identified which covered the management of asymptomatic PAD. Seven guidelines lacked a systematic literature review and nine reported too little information about COI, resulting in low AGREE scores for rigor of development and editorial independence. Ten guidelines contained recommendations about screening with five guidelines at strong strength, three at moderate to strong strength, while others being against it or finding insufficient evidence. ABI test was generally recommended, sometimes with other non-invasive examinations. Its target group is the middle-aged population with increasing cardiovascular risk and elderly. Smoking cessation, hypertension treatment and diabetes therapy were also generally recommended while arterial reconstruction was not indicated. Lipid lowering and antiplatelet therapy were recommended by some guidelines but with controversy in target value.

PAD is a condition with significant morbidity `and mortality, affecting nearly 200 million people worldwide [1]. Notably, nearly $90 \%$ of these individuals are asymptomatic [30]. However, insufficient attention has been paid to these populations. Among the 14 included guidelines, only SVS guideline [26] specially focused on the asymptomatic individuals. Conflicting recommendations were observed both on screening and treatment. For screening for asymptomatic patients, several guidelines supported it at different strength while two were against the screening or considered evidence being insufficient to recommend. AHA/ ACC guideline [18] used invasive and non-invasive angiography as screening methods and is the only included guideline which put screening in the "harm" category. It is worth noting that AHA/ACC guidelines met the threshold for an AGREE II score of "recommended for use in clinical practice", making its recommendations appear to be reliable. The recommendation of screening was mainly on the basis of two studies [31, 32]. Catalano $\mathrm{M}$ et al. [31] conducted a randomized, placebo-controlled, double-blind clinical trial to assess the medical efficacy of aspirin and a high dose antioxidant vitamin combination in PAD patients to reduce the risk of vascular event. However, not all the patients were asymptomatic PAD and $76 \%$ of them were with type 2 diabetes. Minar et al. [32] performed a randomized trial to investigate the effect of different dosage of aspirin in PAD population, rather than the asymptomatic patients. Till now, there was no randomized controlled trial (RCT) directly analyze the effect of screening for PAD in terms of some important outcomes, such as mortality, which is most important for guideline developers to provide recommendations. Since no RCT was avaiable, meta-analyses have been the main source of evidences, but it is not able to reclassify the asymptomatic participants from intermediate to high cardiovascular risk. Fares et al. [30] conducted a meta-analysis in 19 studies and observed large inconsistency in results, which demonstrated the heterogeneity in the risk of the populations and a range of cardiovascular risk among asymptomatic patients. The absence of evidence of high quality and the lager heterogeneity in the selected population might account for the conflicting recommendations in screening.

In terms of treatment, the conflicting recommendations were mainly observed in the target value of lipid lowering and antiplatelet therapy. As it is shown in Table 3, the recommendations from BWG, CEVF and ESC appeared a more aggressive treatment policy, which might be explained by the financial relationship between developers and pharmaceutical industry. In 2011, Institute of Medicine published the standard on conflict of interest, requiring that there should be no COI on committee chairs and less than $50 \%$ of committee members having commercial relationship [33]. According to the standard, only two guidelines (ACCF/AHA, AHA/ACC) met the requirement, indicating that the transparency among guideline writers and industry became a problem. When there is no clear-cut evidence at high quality, the decision may be easily affected by the commercial relationship. The aggressive policy to lower the target value increased the dosage of stain or antiplatelet drug, which might be related to the interest of the industry. Concerning the incomplete information in the included guidelines about potential COI, a transparent development process should be highlighted to ensure that the clinical guidelines establishing appropriate care for asymptomatic PAD patients. Apart from the pharmaceutical treatment and arterial reconstruction, smoking cessation was recommended by five guidelines [16, 19-21, 26]. Smoking has been demonstrated as an important risk factor of PAD [1]. The recommendation of smoking cessation was at level of evidence B in three guidelines [16, 20,21] and at level of evidence A [26] in one guideline. Healthy diet and physical activity were only recommended by ESC guideline [21] while they were not mentioned by others. The recommendation was at the level of evidence $C$ but supporting evidence was not provided. In a word, RCTs in asymptomatic PAD patients should be performed to directly investigate the effect of lifestyle modification.

To make up for the lack of clear-cut evidence as described above and decrease the impact of financial 
relationship with pharmaceutical industry, RCTs of PAD screening versus no screening should be performed in asymptomatic PAD patients. After detection of PAD, interventions are advocated by some included guidelines, which mainly recommend lifestyle intervention, lipid lowing and antiplatelet therapy. However, whether these interventions would be effective in the asymptomatic PAD population is still difficult to answer. The dosage of antiplatelet therapy and target value are also controversy in different guidelines. Without the clear-cut evidence for treatment, the recommendation for medication is more sensitive to conflicts of interest with pharmaceutical industry and biased toward a more aggressive treatment policy. Thus, RCTs for treatment should also be performed to investigate intervention versus no intervention in asymptomatic population. Once the beneficial effect is confirmed, further prospective studies should be carried out to investigate the suitable dosage or target value.

There were several limitations in our study. Firstly, all the selected guidelines were only in English, resulting in the potential selecting bias. Fortunately, even though their official language was not English, some organizations appeared to publish the guidelines in English version. Secondly, we selected AGREE II as the assessment tool, rather than other appraisal tools, such as the four-item Global Rating Scale (GRS) [34]. Although AGREE II instrument has been recognized and widely used in the guideline appraisal $[14,35,36]$, whether results using other appraisal tools are consistent remains unkown. Thirdly, the appraisal using the AGREE instrument was only based on the whole guidelines, rather than specific or individual recommendations. This might weaken the aim of the guideline appraisal which is to provide a whole picture for assessing the quality of reporting recommendations and suggestion on how to improve in the future. Finally, we did not restricted the regions of the included guidelines. Hence, the results may be not that generalizable to readers from the specific region, such as countries with greater or lesser burden of diseases.

\section{Conclusions}

Current guidelines about asymptomatic PAD varied in the methodological quality and fell short of the standard in the rigor of development and editorial independence. The conflicting recommendations were both on the screening and treatment. Increasing effort is needed to provide the clear-cut evidence with high quality and transparency among guideline developers and industry.

\section{Additional files}

Additional file 1: Table S1. Search strategies. (DOCX $17 \mathrm{~kb}$ )
Additional file 2: Table S2. Structure and content of the AGREE instrument. (DOCX $15 \mathrm{~kb}$ )

Additional file 3: Table S3. Data extraction template. (DOCX 14 kb)

\section{Abbreviations}

ACCF AHA: American College of Cardiology Foundation, American Heart Association Task Force; AGREE: Appraisal of Guidelines Research and Evaluation; AHA ACC: American College of Cardiology, American Heart Association Task Force; BWG: Belgian Working Group; CEVF: Central European Vascular Forum; COI: Conflict of Interest; ESC: European Society of Cardiology; GSA: German Society of Angiology; IC: Intermittent Claudication; ISD: Italian Societies of Diabetes; IWGDF: International Working Group on the Diabetic Foot; KSIR: Korean Society of Interventional Radiology; NS: Not Stated; PAD: Peripheral Arterial Disease; SVS: Society for Vascular Surgery;

TASC: Trans-Atlantic Inter-Society Consensus; USPSTF: US Preventive Services Task Force; WHS: Wound Healing Society

\section{Acknowledgements}

Not applicable.

\section{Funding}

This project was funded by the Natural Science Foundation of Guangdong, China (No. 2015A030310346).

\section{Availability of data and materials}

The dataset supporting the conclusions of this article is included within the article.

Guidelines included

ACCF AHA,2013 [16]

ACCP, 2012 [17]

AHA ACC, 2016 [18]

BWG, 2007 [19]

CEVF.2013 [20]

ESC,2017 [21]

GSA,2016 [22]

ISD,2014 [23]

IWGDF,2016 [24]

$\mathrm{KSIR}, 2015$ [25]

SVS,2014 [26]

TASC,2007 [27]

USPSTF,2013 [28]

WHS,2014 [29]

\section{Authors' contributions}

QCC conducted the systemic review, selected and critically appraised the guidelines, collected the data, wrote the draft and revised the manuscript. LLL designed and conducted the systemic review, selected and critically appraised the guidelines, wrote the draft and revised the manuscript. QGC conducted the systemic review, selected the guidelines, collected the data and revised the manuscript. XXL designed the systemic review, conducted the systemic review and revised the manuscript. YHL conducted the systemic review, wrote the draft and revised the manuscript. $\mathrm{KH}$ designed and conducted the systemic review, selected the guidelines, collected the data and revised the manuscript. CY designed and conducted the systemic review, selected and critically appraised the guidelines, collected the data, wrote the draft and revised the manuscript. All authors read the manuscript and made edits for important intellectual content. All authors approved the final manuscript.

Ethics approval and consent to participate

Not applicable.

Consent for publication

Not applicable.

Competing interests

The authors declare that they have no competing interests. 


\section{Publisher's Note}

Springer Nature remains neutral with regard to jurisdictional claims in published maps and institutional affiliations.

\author{
Author details \\ 'Department of Vascular Surgery, the First Affiliated Hospital, Sun Yat-sen \\ University, No.58 Zhongshan Road 2, Guangzhou, China. ${ }^{2}$ Medical Intensive \\ Care Unit, the First Affiliated Hospital, Sun Yat-sen University, No.58 \\ Zhongshan Road 2, Guangzhou, China. ${ }^{3}$ Department of Vascular Surgery, Sun \\ Yat-sen Memorial Hospital, Sun Yat-sen University, No.33, Yingfeng Road, \\ Guangzhou, China.
}

Received: 6 August 2018 Accepted: 20 November 2018 Published online: 15 January 2019

\section{References}

1. Criqui MH, Aboyans V. Epidemiology of peripheral artery disease. Circ Res. 2015;116(9):1509-26.

2. Fowkes FG, Rudan D, Rudan I, Aboyans V, Denenberg JO, McDermott MM, Norman PE, Sampson UK, Williams L, Mensah GA, Criqui MH. Comparison of global estimates of prevalence and risk factors for peripheral artery disease in 2000 and 2010: a systematic review and analysis. Lancet. 2013; 382(9901):1329-40.

3. Ruiz-Canela M, Estruch R, Corella D, Salas-Salvadó J, Martínez-González MA Association of Mediterranean diet with peripheral artery disease: the PREDIMED randomized trial. JAMA. 2014:311(4):415-7.

4. Belch J, MacCuish A, Campbell I, Cobbe S, Taylor R, Prescott R, Lee R, Bancroft J, MacEwan S, Shepherd J, Macfarlane P, Morris A, Jung R, Kelly C, Connacher A, Peden N, Jamieson A, Matthews D, Leese G, McKnight J, O'Brien I, Semple C, Petrie J, Gordon D, Pringle S, MacWalter R. The prevention of progression of arterial disease and diabetes (POPADAD) trial: factorial randomised placebo controlled trial of aspirin and antioxidants in patients with diabetes and asymptomatic peripheral arterial disease. BMJ. 2008;337:a1840.

5. Diehm C, Allenberg JR, Pittrow D, Mahn M, Tepohl G, Haberl RL, Darius H, Burghaus I, Trampisch HJ. Mortality and vascular morbidity in older adults with asymptomatic versus symptomatic peripheral artery disease. Circulation. 2009:120(21):2053-61.

6. Grøndal N, Søgaard R, Henneberg EW, Lindholt JS. The Viborg vascular (VIVA) screening trial of 65-74 year old men in the central region of Denmark: study protocol. Trials. 2010;11(1):67.

7. Diederichsen ACP, Rasmussen LM, Søgaard R, Lambrechtsen J, Steffensen FH, Frost L, Egstrup K, Urbonaviciene G, Busk M, Olsen MH, Mickley H, Hallas J, Lindholt JS. The Danish cardiovascular screening trial (DANCAVAS): study protocol for a randomized controlled trial. Trials. 2015;16(1):554

8. Hoffmann TC, Montori VM, Del Mar C. The connection between evidencebased medicine and shared decision making. JAMA. 2014;312(13):1295-6.

9. Wise J. Still too little transparency among guideline writers and others. BMJ. 2017:356:276.

10. Lin DH, Lucas E, Murimi IB, Kolodny A, Alexander GC. Financial conflicts of interest and the Centers for Disease Control and Prevention's 2016 guideline for prescribing opioids for chronic pain. JAMA Intern Med. 2017; 177(3):427-8.

11. Moher D, Tsertsvadze A, Tricco AC, Eccles M, Grimshaw J, Sampson M, et al. When and how to update systematic reviews. Cochrane Database Syst Rev. 2008;1:MR000023.

12. Vandvik PO, Brandt $L$, Alonso-Coello P, Treweek S, Akl EA, Kristiansen A, FogHeen A, Agoritsas T, Montori VM, Guyatt G. Creating clinical practice guidelines we can trust, use, and share: a new era is imminent. Chest. 2013; 144(2):381-9.

13. Brouwers MC, Kerkvliet K, Spithoff K. The AGREE reporting checklist: a tool to improve reporting of clinical practice guidelines. BMJ. 2016;352:11152.

14. Brouwers MC, Kho ME, Browman GP, Burgers JS, Cluzeau F, Feder G, Fervers B, Graham ID, Grimshaw J, Hanna SE, Littlejohns P, Makarski J, Zitzelsberger L. AGREE II: advancing guideline development, reporting and evaluation in health care. CMAJ. 2010;182(18):E839-42.

15. Nagler EV, Vanmassenhove J, Van der Veer SN, Nistor L, Biesen WV, Webster AC, Vanholder R. Diagnosis and treatment of hyponatremia: a systematic review of clinical practice guidelines and consensus statements. BMC Med. 2014;12(1):231

16. Rooke TW, Hirsch AT, Misra S, Sidawy AN, Beckman JA, Findeiss L, Golzarian J, Gornik HL, Jaff MR, Moneta GL, Olin JW, Stanley JC, White CJ, White JV,
Zierler RE. Management of patients with peripheral artery disease (compilation of 2005 and 2011 ACCF/AHA guideline recommendations): a report of the American College of Cardiology Foundation/American Heart Association task force on practice guidelines. J Am Coll Cardiol. 2013;61(14): 1555-70.

17. Kearon C, Akl EA, Comerota AJ, Prandoni P, Bounameaux H, Goldhaber SZ Nelson ME, Wells PS, Gould MK, Dentali F, Crowther M, Kahn SR. Antithrombotic therapy for VTE disease: antithrombotic therapy and prevention of thrombosis: American College of Chest Physicians evidencebased clinical practice guidelines. Chest. 2012;141(2):e419S-96S.

18. Gerhard-Herman MD, Gornik HL, Barrett C, Barshes NR, Corriere MA, Drachman DE, Fleisher LA, Fowkes FG, Hamburg NM, Kinlay S, Lookstein R, Misra S, Mureebe L, Olin JW, Patel RA, Regensteiner JG, Schanzer A, Shishehbor MH, Stewart KJ, Treat-Jacobson D, Walsh ME. 2016 AHA/ACC guideline on the management of patients with lower extremity peripheral artery disease: executive summary: a report of the American College of Cardiology/American Heart Association task force on clinical practice guidelines. Circulation. 2017;135(12):e686-725.

19. Clement D, Kolh P, Motte S, Sprynger M, Van Damme H, Verhamme P, Vermassen F, Wautrecht JC. Diagnosis and treatment of peripheral arterial disease: recommendations for the medical practice in Belgium. Acta Chir Belg. 2007;107(6):595-604.

20. Andreozzi GM, Arosio E, Martini R, Verlato F, Visonà A. Consensus Document on Intermittent Claudication from the Central European Vascular Forum 1st edition-Abano Terme (Italy)-May 2005 2nd revision-Portroz (Slovenia)September 2007. Int Angiol. 2008;27(2):93.

21. Aboyans V, Björck M, Brodmann M, Collet JP, Czerny M, De Carlo M, Naylor AR, Roffi M, Tendera M, Vlachopoulos C, Ricco JB, Reviewers D, Widimsky P, Kolh P, Dick F, de Ceniga MV, Piepoli MF, Sievert H, Sulzenko J, Esc Committee For Practice Guidelines Cpg, Windecker S, Aboyans V, Agewall S, Barbato E, Bueno H, Coca A, Collet JP, Coman IM, Dean V, Delgado V, Fitzsimons D, Gaemperli O, Hindricks G, lung B, Jüni P, Katus HA, Knuuti J, Lancellotti P, Leclercq C, McDonagh T, Piepoli MF, Ponikowski P, Richter DJ, Roffi M, Shlyakhto E, Simpson IA, Zamorano JL. 2017 ESC quidelines on the diagnosis and treatment of peripheral arterial diseases, in collaboration with the European Society for Vascular Surgery (ESVS) document covering atherosclerotic disease of extracranial carotid and vertebral, mesenteric, renal, upper and lower extremity arteries endorsed by: the European stroke organization (ESO) the task force for the diagnosis and treatment of peripheral arterial diseases of the European Society of Cardiology (ESC) and of the European Society for Vascular Surgery (ESVS). Eur Heart J. 2017;39(9):763-816.

22. Lawall $H$, Huppert $P$, Espinola-Klein $C$, Rümenapf $G$. The diagnosis and treatment of peripheral arterial vascular disease. Deutsch Ärztebl Int. 2016;113(43):729.

23. Aiello A, Anichini R, Brocco E, Caravaggi C, Chiavetta A, Cioni R, Da Ros R, De Feo ME, Ferraresi R, Florio F, Gargiulo M, Galzerano G, Gandini R, Giurato L, Graziani L, Mancini L, Manzi M, Modugno P, Setacci C, Uccioli L. Treatment of peripheral arterial disease in diabetes: a consensus of the Italian societies of diabetes (SID, AMD), radiology (SIRM) and vascular endovascular surgery (SICVE). Nutr Metab Cardiovasc Dis. 2014;24(4):355-69.

24. Hinchliffe RJ, Brownrigg JR, Apelqvist J, Boyko EJ, Fitridge R, Mills JL, Reekers J, Shearman CP, Zierler RE, Schaper NC. IWGDF guidance on the diagnosis, prognosis and management of peripheral artery disease in patients with foot ulcers in diabetes. Diabetes Metab Res Rev. 2016:32:37-44.

25. Kim YH, Bae Jl, Jeon YS, Kim CW, Jae HJ, Park KB, Cho YK, Kim MD. Korean guidelines for interventional recanalization of lower extremity arteries. Korean J Radiol. 2015;16(4):696-722.

26. Conte MS, Pomposelli FB. Society for Vascular Surgery practice guidelines for atherosclerotic occlusive disease of the lower extremities: management of asymptomatic disease and claudication. J Vasc Surg. 2015:61(3):2S-41S. e1.

27. Norgren L, Hiatt WR, Dormandy JA, Nehler MR, Harris KA, Fowkes FGR. Intersociety consensus for the management of peripheral arterial disease (TASC II). J Vasc Surg. 2007;45(1):S5-S67.

28. Moyer VA. Screening for peripheral artery disease and cardiovascular disease risk assessment with the ankle-brachial index in adults: US preventive services task force recommendation statement. Ann Intern Med. 2013; 159(5):342-8.

29. Federman DG, Ladiiznski B, Dardik A, Kelly M, Shapshak D, Ueno CM, Mostow EN, Richmond NA, Hopf HW. Wound healing society 2014 update on guidelines for arterial ulcers. Wound Repair Regen. 2016; 24(1):127-35 
30. Alahdab F, Wang AT, Elraiyah TA, Malgor RD, Rizvi AZ, Lane MA, Prokop ${ }^{\prime}$ Montori VM, Conte MS, Murad MH. A systematic review for the screening for peripheral arterial disease in asymptomatic patients. J Vasc Surg. 2015; 61(3):42S-53S.

31. Critical Leg Ischaemia Prevention Study (CLIPS) Group. Prevention of serious vascular events by aspirin amongst patients with peripheral arterial disease: randomized, double-blind trial. J Intern Med. 2007; 261(3):276-84

32. Minar E, Ahmadi A, Koppensteiner R, Maca T, Stümpflen A, Ugurluoglu A, Ehringer $\mathrm{H}$. Comparison of effects of high-dose and low-dose aspirin on restenosis after femoropopliteal percutaneous transluminal angioplast. Circulation. 1995;91(8):2167-73.

33. Graham R, Mancher M, Miller Wolman D, Greenfield S, Steinberg E. Committee on standards for developing trustworthy clinical practice guidelines; institute of medicine. Clinical practice guidelines we can trust; 2011.

34. Brouwers MC, Kho ME, Browman GP, Burgers JS, Cluzeau F, Feder G, Fervers B, Graham ID, Grimshaw J, Hanna SE, Littlejohns P. Makarski J, Zitzelsberger L. The global rating scale complements the AGREE II in advancing the quality of practice guidelines. J Clin Epidemiol. 2012;65(5):526-34.

35. Ferket BS, Genders TSS, Colkesen EB, Visser JJ, Spronk S, Steyerberg EW, Hunink MGM. Systematic review of quidelines on imaging of asymptomatic coronary artery disease. J Am Coll Cardiol. 2011;57(15):1591-600

36. Huang TW, Lai JH, Wu MY, Chen SL, Wu CH, Tam KW. Systematic review of clinical practice guidelines in the diagnosis and management of thyroid nodules and cancer. BMC Med. 2013;11(1):191.

Ready to submit your research? Choose BMC and benefit from:

- fast, convenient online submission

- thorough peer review by experienced researchers in your field

- rapid publication on acceptance

- support for research data, including large and complex data types

- gold Open Access which fosters wider collaboration and increased citations

- maximum visibility for your research: over $100 \mathrm{M}$ website views per year

At $\mathrm{BMC}$, research is always in progress.

Learn more biomedcentral.com/submissions 